\title{
Editorial
}

\section{What is a brand worth?}

Journal of Brand Management (2008) 15, 155-156. doi:10.1057/palgrave.bm.2550135

It is a privilege to be appointed to the Editorial Board of the Journal of Brand Management and be invited to write my inaugural editorial for this issue.

My own area of specific interest is Integrated Marketing Communications (IMC) and in so many ways 'the brand' and 'branding' is the embodiment of IMC. The brand is, after all, the sum total and ultimate expression of all the collected activities undertaken by the brand owner (or on the owner's behalf) and the experiences of the brand user. These activities and experiences do not always match, work in accord or act synergistically in an integrative way to achieve the best out of the brand's potential. But, surely, it should be our aim to achieve such synergy, not just narrowly in a single campaign or over a single campaign period, but over an extended period of time. And, herein, lies our challenge. How should our efforts and our customer/consumer experiences be measured and valued? What is the brand worth?

Of course, the driving forces for such measurement are many and varied and represent diverse, vested interests. Over more recent times, the imperative has been the balance sheet: to find a specific financial number that represents brand worth. However strong this imperative may be to find a single expression of outcome, this should not detract from the need to seek measures that offer opportunities that allow us to glimpse into those workings of brand management that eventually result in brand worth. This involves investigation into, and an understanding of, the way in which a host of individual aspects of branding are brought together to create the coherent brand whole.

While I have seen many examples and heard many arguments about how individual elements of branding may be measured, there is no satisfactory resolution as to how the integration of these may be measured or assessed, despite the common acceptance of the power of synergistic effects: the 'two plus two equals five' phenomenon in which the bringing together of elements has a greater effect than the simple sum of the individual elements themselves. Arguments may rage, and they are destined to continue to do so, as long as the focus of attention is on the effectiveness of the outcomes of branding.

I would argue an alternative view. It is not peculiarly my own, I merely promulgate it. Some refer to this as distinguishing between 'output' or 'outcome' measures versus 'input' or 'process' measures. A switch of emphasis towards process re-directs attention towards assessing the inputs into brand management. Process measures are more about the resources used in brand building: the budgets spent; the expertise used; the selection and integration of audiences targeted; the management and integration of staff, both internal and external agencies, involved in branding; the interweaving of individual campaigns and creative treatments used for each element of the promotional mix and used over time; the use and management of databases pertinent to the brand; the geographical integration of the brand; the interplay between corporate branding and 
the individual brand; and so on. One should not look at these individually only but, importantly, as a complete process-whether this process is functional or dysfunctional or, more likely, the shades of grey between the two extremes. And one should recognise within such evaluation the impact that lack of integration brings. Lack of integration is not a neutral situation. It can lead to dysfunction, negative consequences and opportunity costs; the impact of both integration and the lack of integration should not, in my opinion, be underestimated.

This might be described as a drive to examine the brand's ecosystem. It is an ecosystem that shares, in common with other natural ecosystems, a multiplicity of actions and reactions, individual responses that mean little in themselves but have power in their gathering, positive and negative forces that come together in the integration that is the ecosystem itself: its synergy and, significantly, its symbiosis in which the roles of the different parts of the ecosystem are valued, however small they may appear to be, for without them other parts of the system may cease to function. And whatever may be the outcomes of the ecosystem in terms of brand sales, profits, volumes, equity or value, and whether we assess the adver- tising, identity and image, and other cues of the brand that we manipulate as successful, we should at least be able to better understand the management processes that go into generating those outcomes. In this way branding is clearly recognised as a managerial process in which we seek to become more economical, efficient and effective by managing the inputs that in due course result in a given set of outputs. Put crudely, the plea is to place greater emphasis on assessing process, as opposed to outcome; outputs are a function of inputs. And perhaps to labour the point, more needs to be done to measure the interaction of the individual actions as an integrative whole: as a complete system, and not just an evaluation of each element that goes into the process. We need to ask the questions, 'How might we evaluate the impact of integration itself?' and 'What might we learn from this evaluation to improve the process of brand management?' I have some of my own ideas. I would like to encourage all those who have adopted such perspectives in their research, consultancy and efforts to continue to do so and to publish their approaches and papers in this journal.

\section{David Pickton Editorial Board}

